\title{
Impact of real-time use of artificial intelligence in improving adenoma detection during colonoscopy: A systematic review and meta-analysis
}

다(1)이우

\author{
Authors \\ Institutions \\ 1 Department of Gastroenterology and Hepatology, \\ University of lowa Hospitals and Clinics, lowa City, lowa, \\ United States \\ 2 Digestive Disease Institute, Virginia Mason Medical \\ Center, Seattle, Washington, United States \\ 3 Division of Gastroenterology and Hepatology, Mayo \\ Clinic, Rochester, New York, United States
}

Munish Ashat ${ }^{1}$, Jagpal Singh Klair ${ }^{2}$, Dhruv Singh ${ }^{3}$, Arvind Rangarajan Murali ${ }^{1}$, Rajesh Krishnamoorthi

submitted 24.6.2020

accepted after revision 23.11 .2020

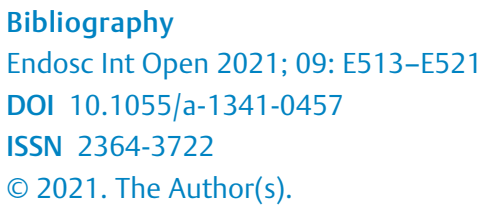
Commons Attribution-NonDerivative-NonCommercial License, permitting copying and reproduction so long as the original work is given appropriate credit. Contents may not be used for commercial purposes, or adapted, remixed, transformed or built upon. (https://creativecommons.org/licenses/by-nc-nd/4.0/)

Georg Thieme Verlag KG, Rüdigerstraße 14,

70469 Stuttgart, Germany

Corresponding author

Rajesh Krishnamoorthi, MD, Division of Gastroenterology and Hepatology, Virginia Mason Medical Center, 1100 Ninth Avenue, Seattle, WA 98101, United States Rajesh.Krishnamoorthi@virginiamason.org

\author{
丹 Supplementary material is available under \\ https://doi.org/10.1055/a-1341-0457
}

\section{ABSTRACT}

Background and study aims With the advent of deep neural networks (DNN) learning, the field of artificial intelligence (AI) is rapidly evolving. Recent randomized controlled trials (RCT) have investigated the influence of integrating $\mathrm{Al}$ in colonoscopy and its impact on adenoma detection rates (ADRs) and polyp detection rates (PDRs). We performed a systematic review and meta-analysis to reliably assess if the impact is statistically significant enough to warrant the adoption of $\mathrm{Al}$-assisted colonoscopy (AIAC) in clinical practice.

Methods We conducted a comprehensive search of multiple electronic databases and conference proceedings to identify RCTs that compared outcomes between AIAC and conventional colonoscopy (CC). The primary outcome was ADR. The secondary outcomes were PDR and total withdrawal time (WT).

Results Six RCTs (comparing AIAC vs CC) with 5058 individuals undergoing average-risk screening colonoscopy were included in the meta-analysis. ADR was significantly higher with AIAC compared to CC (33.7\% versus $22.9 \%$; odds ratio (OR) 1.76, $95 \%$ confidence interval (CI) 1.55$\left.2.00 ; 1^{2}=28 \%\right)$. Similarly, PDR was significantly higher with AIAC (45.6\% versus 30.6\%; OR 1.90, 95\% Cl, 1.68-2.15, $\left.\mathrm{I}^{2}=0 \%\right)$. The overall WT was higher for AIAC compared to CC (mean difference [MD] $0.46(0.00-0.92)$ minutes, $\mathrm{I}^{2}=94 \%$ ). Conclusions There is an increase in adenoma and polyp detection with the utilization of AIAC.

\section{Introduction}

Colorectal cancer (CRC) is one of the leading causes of cancerrelated death [1], and colonoscopy remains the best modality for CRC screening [2,3]. Screening colonoscopy not only reduces the incidence of CRC but also reduces CRC-related mortality [4]. This is achieved by the detection and removal of precancerous adenomatous polyps. Adenoma detection rate (ADR) is an important quality indicator of colonoscopy, and increasing ADR by $1.0 \%$ could reduce CRC-related mortality by $3 \%$ and interval cancer by up to $5 \%$ [5]. The quality metric established by the American Society of Gastrointestinal Endoscopy recommends a target ADR of $30 \%$ in men and $20 \%$ in women (25\% average ADR) [6]. However, studies have reported missed adenoma rates of up to $27 \%$ [7]. Several factors could contribute to it, including polyp characteristics (location and size), prep quality, 
and inadequate inspection or lack of recognition of sessile polyps by endoscopists.

The inclusion of a second observer has shown to increase ADR [8]. With the advancement in machine learning capabilities over the past decade, multiple studies have investigated the potential of Al to serve as a second observer to help improve quality indicators of colonoscopy, including ADR, poly detection rate (PDR), and withdrawal time (WT) [9-13]. Al, with the use of a deep neural network (DNN), is designed to work like a human brain via multiple layers of neural networks that are stacked onto one another. Each neural network is composed of a computational hub called nodes, and the nodes are interconnected and structured into multiple layers. This multilayered computation structure gives DNN the ability to scan input images and videos (in this case, colonoscopy images/videos) and detect required output (adenoma/polyps). Although we have known about the DNN system since the 1980 s, the recent advances in technology have enabled computers to handle vast amounts of computations data required to establish an effective DNN system [14].

Different DNN systems have been established to aid gastroenterologists in improving quality metrics for colonoscopy, including ADRs. An effective DNN system should have high sensitivity and specificity. Previous retrospective studies have estimated the diagnostic accuracy of DNN systems to detect polyps as $89 \%$ to $95 \%$ [15-17] with a sensitivity of greater than $90 \%[17,18]$. Recent RCTs comparing AIAC with CC have investigated the impact of $\mathrm{Al}$ on overall ADRs and PDRs [913]. We performed a systematic review and meta-analysis with the primary aim to reliably assess if the impact of AIAC on ADR is statistically significant enough that it needs to be adopted in clinical practice. The secondary aim of the meta-analysis was to evaluate the impact of AIAC on PDR and WT.

\section{Materials and methods}

This systematic review was performed in accordance with the Cochrane Handbook for Systematic Reviews of Interventions. It is reported following Preferred Reporting Items for Systematic Reviews and Meta-Analyses (PRISMA) guidelines.

\section{Search strategy}

We conducted a comprehensive search of several databases and conference proceedings, including Medline, EMBASE, Scopus, Cochrane Library, and Web of Science databases were searched through April 2020 to identify RCTs that compared outcomes between AIAC and CC. The literature search was performed by an experienced medical librarian using input from the study authors. The details of the search strategy and data sources are reported in Appendix 1.

Keywords used in the search included a combination of artificial intelligence (AI), neural networks, deep learning, colonoscopy, colon polyps, polyp detection, and adenoma detection rates. The search was restricted to studies in human subjects published in the English language. Two authors (MA, JSK) independently reviewed the title and abstract of studies identified in the primary search and excluded studies that were not rele- vant to the research question based on prespecified inclusion and exclusion criteria. The full text of the remaining articles was reviewed to determine whether it reported outcomes of interest. Any discrepancy in article selection was resolved by consensus and in discussion with a co-author. The bibliographic sections of the selected articles, as well as narrative reviews on the topic, were also manually searched for additional relevant studies.

\section{Selection criteria}

In the meta-analysis, we included studies that met the following inclusion criteria (1) RCTs that compared AIAC vs. CC for the screening of CRC; and (2) reported ADR and/or PDR for the two groups. We excluded; (1) computations analysis studies (which involved retrospective analyses of colonoscopy images/ videos to generate a DNN system with the assessment of ADR based on image analysis without patient enrollment or control arm); (2) studies in which an Al system was used for histopathological characterization of polyps rather than ADR; (3) that were in the non-English languages; (4) non-human studies; and (5) letters to editors, case reports, retrospective studies, review articles and editorials, and duplicate studies.

\section{Data abstraction and quality assessment}

After identifying relevant studies, data on the study characteristics, patient characteristics, and outcomes of interest (ADR, PDR, adenoma location and size, and WT) were abstracted independently by two authors (MA, JSK) onto a standardized form. The quality of evidence was assessed using Grading of Recommendation Assessment, Development, and Evaluation (GRADE) approach. The assessment was performed by two authors (MA, JSK) independently. Overall quality was then deemed as very low, low, moderate, and high using the GRADE Tool [19].

\section{Assessment of risk of bias}

The Cochrane tool was used to assess for risk of bias [20,21]. Two authors (MA, JSK) independently assessed each RCT for the risk of bias. The risk in each study was rated as high, low, or unclear for each of the five domains of the tool: random sequence generation (selection bias), allocation concealment (selection bias), blinding of participants (performance bias), blinding of outcome assessment (detection bias), incomplete outcome data (attrition bias), and selective reporting (reporting bias).

\section{Outcome assessed}

The primary outcome of the study was to assess the impact of AI on ADR. The secondary outcomes included PDR and total WT. We also performed a separate analysis to assess the impact of AIAC in detecting adenomas stratified by their location (in proximal versus distal colon with the splenic flexure being the cutoff) and size (0-5 mm, 6-10 mm, and $>10 \mathrm{~mm})$. 


\section{Statistical analysis}

Pooled odds ratio (OR) for dichotomous variables and mean differences (MD) for continuous variable and their $95 \%$ confidence intervals $(\mathrm{Cl})$ were calculated for the outcomes of interest. The Mantel-Haenszel method was used to calculate the OR, and the inverse variance method was used to calculate the MD. The $X^{2}$ test (Cochran $Q$ statistic) was used to evaluate heterogeneity between studies and was quantified using the $\mathrm{i}^{2}$ statistic. Heterogeneity was assigned as low, moderate, substantial and high based on $\mathrm{i}^{2}$ values of $<25 \%, 26 \%$ to $50 \%, 51 \%$ to $75 \%$ and $>75 \%$, respectively. We planned to assess for publication bias qualitatively by visual inspection of a funnel plot, and quantitatively by the Egger test (Supplementary Fig. 1 and Supplementary Fig. 2) [22]. All analyses were performed using the Review Manager 5.3 (The Cochrane Collaboration, Oxford, UK). Two-sided testing was used. $P<0.05$ was considered significant.

\section{Results}

A total of 2122 studies were identified by our search criteria; 116 studies were identified after removing duplicate records, animal studies, retrospective studies, and computational analysis. After full-text review of 116 studies, 109 studies were excluded as outcomes reported were not relevant to the current meta-analysis. One additional study was excluded, as it was not a comparative study between AIAC and CC [23]. A total of six studies with a total of 5058 patients that met our inclusion criteria were included in the meta-analysis. The schematic diagram of study identification and selection is illustrated in - Fig. 1.

\section{Characteristics and quality of the studies}

The study characteristics of individual studies are summarized in $>$ Table 1 and $>$ Table 2 . All six studies were RCTs. All the included studies were from China except one by Recipi et al [24], which was done in Italy. All studies were single-center except for the study by Recipi et al [24], which was a multicenter study. There was no difference in the adequacy of bowel prep (based on the Boston Bowel Preparation Scale) between the two groups (AIAC vs CC) in the individual studies ( $\triangleright$ Table 2 ). Colonoscopes from different manufacturers were used in the individual studies. A summarized assessment of the risk of bias in each study using the Cochrane tool is illustrated in Supplementary Table 1. Supplementary Table 2 summarizes the assessment of quality of evidence using the GRADE approach [19].

\section{Adenoma detection rate}

ADRs in the six included studies (AIAC vs CC) are summarized in - Table 2. On pooled analysis, the ADR was significantly higher with AIAC compared to CC (33.7\% vs $22.9 \%$; OR $1.76 ; 95 \% \mathrm{Cl}$, 1.55-2.00; $P<0.001)$ ( $\triangleright$ Fig. 2, $\triangleright$ Table 3 ). There was moderate heterogeneity $\left(I^{2}=28 \%\right)$ in the analysis. GRADE analysis indicated the quality of evidence supporting higher ADR with AIAC was moderate (Supplementary Table 2).

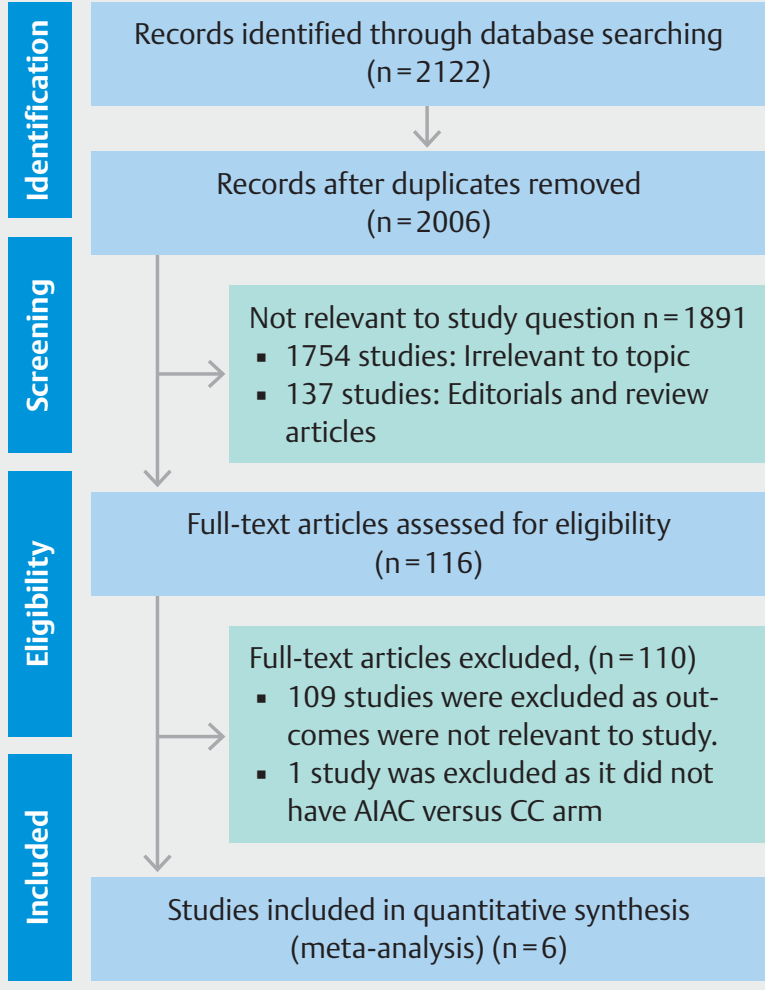

- Fig. 1 Flowchart summarizing the study selection process.

\section{Polyp detection rate}

The PDRs in the five included studies (AIAC vs CC) are summarized in > Table 2. The PDR was significantly higher with AIAC as compared to CC (45.61\% vs 30.69\%; $P<0.001$; OR 1.90 ; $95 \% \mathrm{Cl}$,

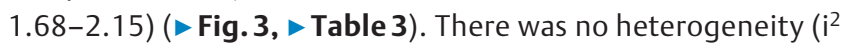
$=0 \%)$ in the analysis. GRADE analysis indicated the quality of evidence supporting higher PDR with AIAC was moderate (Supplementary Table 2).

\section{Withdrawal time}

Five studies $[9,10,12,13,24]$ were included in this pooled analysis as one of the studies [11] did not report data on overall WT. Overall WT was higher with AIAC as compared to CC (MD 0.46; 0.00-0.92 minute; $P<0.001, \mathrm{i}^{2}=94 \%$ ) ( $\triangleright$ Fig. 4). The mean (SD) WT with AIAC was 6.92 (1.99) minutes. However, no polyp WT was similar between the two groups in the three studies $[10,12,13]$ that reported these data (MD 0.05; -0.03-0.12 minute; $P=0.21, \mathrm{i}^{2}=0 \%$ ) ( Fig. 4 ).

\section{ADR by adenoma location}

The ADRs based on adenoma location in the five included studies (AIAC vs CC) are summarized in > Table 2. AIAC identified significantly more adenomas in the proximal colon compared to CC $(23.1 \%$ vs $14.5 \%$, OR $1.81,95 \% \mathrm{Cl}, 1.57-2.10 ; P<0.001)$. Similarly, AIAC identified significantly more polyps in the distal colon compared to CC (OR 2.00 [1.71-2.35]; $P<0.001)$. There 
Table 1 Patient demographics of individual studies.

\begin{tabular}{|c|c|c|c|c|c|c|c|c|c|}
\hline \multirow{2}{*}{$\begin{array}{l}\text { Study } \\
\text { details| } \\
\text { year of } \\
\text { publication }\end{array}$} & \multirow[t]{2}{*}{$\begin{array}{l}\text { Coun- } \\
\text { try }\end{array}$} & \multirow[t]{2}{*}{$\begin{array}{l}\text { Study } \\
\text { design }\end{array}$} & \multirow{2}{*}{$\begin{array}{l}\text { Total } \\
\text { number } \\
\text { of pa- } \\
\text { tients }\end{array}$} & \multicolumn{2}{|c|}{ Screening modality } & \multicolumn{2}{|c|}{ Mean age in years (SD) } & \multicolumn{2}{|l|}{$\begin{array}{l}\text { Sex ratio } \\
\text { (M:F) }\end{array}$} \\
\hline & & & & $\begin{array}{l}\text { Artificial in- } \\
\text { telligence-ai- } \\
\text { ded colonos- } \\
\text { copy (AIAC) }\end{array}$ & $\begin{array}{l}\text { Conven- } \\
\text { tional colo- } \\
\text { noscopy } \\
\text { (CC) }\end{array}$ & AIAC & CC & AIAC & CC \\
\hline $\begin{array}{l}\text { Wang Pu et } \\
\text { al (2019) }\end{array}$ & China & RCT & 1058 & 522 & 536 & $51.07(13.15)$ & $49.94(13.79)$ & $263: 259$ & $249: 287$ \\
\hline $\begin{array}{l}\text { Gong et al } \\
\text { (2020) }\end{array}$ & China & RCT & 704 & 355 & 349 & $50(37-58)$ & $49(36-57)$ & $187: 168$ & 158:191 \\
\hline $\begin{array}{l}\text { Wang Pu et } \\
\text { al (2020) }\end{array}$ & China & $\mathrm{RCT}$ & 1010 & 508 & 502 & $49(39-60)$ & $49(40-56)$ & $241: 243$ & $254: 224$ \\
\hline $\begin{array}{l}\text { Liu et al } \\
\text { (2019) }\end{array}$ & China & RCT & 1026 & 508 & 518 & $51.02(12.26)$ & $50.13(12.68)$ & $264: 244$ & $287: 231$ \\
\hline $\begin{array}{l}\text { Su et al } \\
(2020)\end{array}$ & China & RCT & 659 & 308 & 315 & $50.54(10.28)$ & $51.63(9.04)$ & 159:149 & $148: 167$ \\
\hline Recipi et al & Italy & $\mathrm{RCT}$ & 685 & 341 & 344 & $61(9.7)$ & $61.1(0.44)$ & $172: 169$ & $165: 179$ \\
\hline
\end{tabular}

was low heterogeneity in both analyses $\left(i^{2}=22 \%\right.$ and $i^{2}=0 \%$ respectively) ( $\triangleright$ Fig. 5 and Supplementary Table 2 ).

\section{ADR by adenoma size}

On stratification of adenomas by size, AIAC was superior to CC in identification of adenomas of $0-5 \mathrm{~mm}$ (OR 2.07, 1.81-2.36; $P<0.001, \mathrm{i}^{2}=27 \%$ ), 6-10 mm (OR 1.47, 1.19-1.82; $P=0.004$, $\left.\mathrm{i}^{2}=0 \%\right)$ and $>10 \mathrm{~mm}\left(\mathrm{OR} 1.79,1.27-2.53 ; P<0.001, \mathrm{i}^{2}=12 \%\right)$ (Supplementary Fig. 3).

\section{Publication bias}

Assessment for publication bias was not performed because there were $<10$ studies included in the meta-analysis.

\section{Discussion}

With the advent of effective screening modalities, the overall incidence of colon cancer has been decreasing over the past two decades [25]. Nevertheless, CRC remains the third most common cancer worldwide [1]. Colonoscopy is regarded as a gold standard test for CRC screening and is routinely performed for both screening and surveillance of CRC. Development of CRC before the recommended follow-up colonoscopy, also known as "interval cancer" accounts for up to $9 \%$ of all colon cancers in Canada and the United States. Almost $85 \%$ of these interval cancers are thought to have developed because of either missed polyp or incomplete polyp resection [26]. The overall effectiveness of screening colonoscopy in decreasing CRC incidence can be operator dependent [27] as there is still a substantial variation in performance statistics between physicians. ADR is a well-accepted quality indicator for colonoscopy, but there is a wide variation in reported rates (7 to $53 \%$ ) [28]. Various newer modalities have been studied to help increase ADR. Some of these interventions include changes in procedure techniques like water immersion and water exchange, add-on devices like Endo-Cuff, cap-assisted colonoscopy, image enhancement with narrow-band imaging (NBI) or chromoendoscopy [29-32] and DNN based computer learning capabilities. While AIAC has shown promising results in improving ADR in the recent RCTs, it is unclear if the impact is significant enough to warrant changes in clinical practice.

In the current meta-analysis of five RCTs with 5058 patients that compared AIAC vs CC, the use of AIAC was associated with significantly higher ADR (33.7\% versus $22.9 \%$; OR 1.76 ; $95 \% \mathrm{Cl}$, $1.55-2.00 ; P<0.001,12=28 \%)$ and PDR (45.61\% versus $30.69 \%$; OR 1.90; $\left.95 \% \mathrm{Cl}, 1.68-2.15 ; P<0.001, I^{2}=0 \%\right)$. Comparing specific ADRs based on adenoma location and size, AIAC was associated with significantly higher ADRs compared to CC. While there was an increase in the mean WT with AIAC, this was minimal (46 seconds). To the best of our knowledge, this is the first meta-analysis of randomized controlled trials (RCTs) evaluating the impact of AIAC on improving adenoma and PDRs in screening colonoscopy.

As AIAC is associated with significantly higher ADR compared to $C C$, it is possible that the risk of interval cancers could be lower with use of AIAC given that ADR is inversely proportional to the incidence of interval cancers. While CRC screening with colonoscopy significantly decreases the overall incidence of CRC and related mortality, it has been ineffective in decreasing the incidence of proximal colon cancers and mortality [33, 34]. This could be explained by higher missed proximal (right-sided) adenoma detection [33]. In the current meta-analysis, we noted that AIAC significantly increases ADR in the proximal colon compared to CC (23.1\% vs $14.5 \%$; OR 1.81 ; $95 \% \mathrm{Cl}, 1.57-2.10$; $P<0.001)$ and hence could potentially decrease the incidence of proximal interval cancers. 
- Table2 Characteristics of individual studies.

\begin{tabular}{|c|c|c|c|c|c|c|c|c|}
\hline Study details & & & $\begin{array}{l}\text { Wang Pu } \\
\text { et al (2019) }\end{array}$ & $\begin{array}{l}\text { Gong et al } \\
(2020)\end{array}$ & $\begin{array}{l}\text { Wang Pu } \\
\text { et al (2020) }\end{array}$ & $\begin{array}{l}\text { Liu et al } \\
\text { (2019) }\end{array}$ & $\begin{array}{l}\text { Su et al } \\
(2020)\end{array}$ & $\begin{array}{l}\text { Recipi et } \\
\text { al (2020) }\end{array}$ \\
\hline \multicolumn{9}{|c|}{ Primary outcome } \\
\hline \multirow{2}{*}{$\begin{array}{l}\text { Adenoma de- } \\
\text { tection rate (\%) }\end{array}$} & AIAC & & 29 & 16 & 34 & 39 & 28.9 & 54.8 \\
\hline & $\mathrm{CC}$ & & 20 & 8 & 28 & 23 & 16.5 & 40.4 \\
\hline \multicolumn{9}{|c|}{ Secondary outcomes } \\
\hline \multirow{2}{*}{$\begin{array}{l}\text { Polyp detec- } \\
\text { tion rate (\%) }\end{array}$} & AIAC & & 45 & 47 & 52 & 44 & 38.3 & - \\
\hline & $\mathrm{CC}$ & & 29 & 34 & 37 & 28 & 25.4 & - \\
\hline \multirow{6}{*}{$\begin{array}{l}\text { Adenoma size } \\
\text { (in } \mathrm{mm} \text { ) }\end{array}$} & \multirow[t]{3}{*}{ AIAC } & $0-5$ & 185 & 46 & 211 & 166 & - & 115 \\
\hline & & $6-10$ & 61 & 4 & 60 & 63 & - & 36 \\
\hline & & $>10$ & 16 & 10 & 10 & 21 & - & 36 \\
\hline & \multirow[t]{3}{*}{$\mathrm{CC}$} & $0-5$ & 102 & 25 & 128 & 89 & - & 91 \\
\hline & & $6-10$ & 50 & 1 & 46 & 43 & - & 20 \\
\hline & & $>10$ & 8 & 1 & 7 & 10 & - & 28 \\
\hline \multirow{12}{*}{$\begin{array}{l}\text { Location of } \\
\text { adenoma }\end{array}$} & AIAC & Cecum, n (\%) & $3(1.15)$ & $1(0.6)$ & $5(2)$ & $6(2.4)$ & $3(2.65)$ & - \\
\hline & & Ascending, $\mathrm{n}(\%)$ & 47 (17.94) & $10(3)$ & $62(22)$ & $50(20)$ & $17(15.04)$ & - \\
\hline & & Transverse, n (\%) & $72(27.48)$ & $15(4)$ & $65(23)$ & $75(30)$ & $28(24.78)$ & - \\
\hline & & Descending, n (\%) & 44 (16.79) & $7(2)$ & $46(16)$ & $48(19.2)$ & $21(18.58)$ & - \\
\hline & & Sigmoid, n (\%) & $64(24.43)$ & $19(5)$ & $70(25)$ & $35(14)$ & $29(25.66)$ & - \\
\hline & & Rectum, n (\%) & $32(12.21)$ & $9(3)$ & $33(12)$ & $36(14.4)$ & $15(13.27)$ & - \\
\hline & $\mathrm{CC}$ & Cecum, n (\%) & $1(0.62)$ & $2(1)$ & $5(3)$ & $3(2.11)$ & $1(1.79)$ & - \\
\hline & & Ascending, $\mathrm{n}(\%)$ & $39(24.38)$ & $4(1)$ & $41(23)$ & $40(28.17)$ & $6(10.71)$ & - \\
\hline & & Transverse, n (\%) & $36(22.50)$ & $6(2)$ & $39(22)$ & $38(26.76)$ & $11(19.64)$ & - \\
\hline & & Descending, n (\%) & $20(12.50)$ & $2(1)$ & $31(17)$ & $22(15.49)$ & $10(17.86)$ & - \\
\hline & & Sigmoid, n (\%) & $41(25.62)$ & $9(3)$ & $44(24)$ & 20 (14.09) & $16(28.57)$ & - \\
\hline & & Rectum, n (\%) & $23(14.37)$ & $4(1)$ & $21(12)$ & $19(13.38)$ & $12(21.43)$ & - \\
\hline \multirow[t]{4}{*}{ Colon prep } & AIAC & $\begin{array}{l}\text { Inadequate Boston } \\
\text { Prep Scale n (\%) }\end{array}$ & $73(13.98)$ & $21(6)$ & $71(15 \%)$ & $66(12.9)$ & NR & $2(1 \%)$ \\
\hline & & $\begin{array}{l}\text { Adequate Boston } \\
\text { Prep Scale n (\%) }\end{array}$ & $449(86.02)$ & & $413(85 \%)$ & $442(87.1)$ & NR & $339(99.4)$ \\
\hline & $\mathrm{CC}$ & $\begin{array}{l}\text { Inadequate Boston } \\
\text { Prep Scale n (\%) }\end{array}$ & $79(14.74)$ & $22(6)$ & $65(14 \%)$ & $71(13.71)$ & NR & $2(<1)$ \\
\hline & & $\begin{array}{l}\text { Adequate Boston } \\
\text { Prep Scale n (\%) }\end{array}$ & $457(85.26)$ & & $413(86 \%)$ & $447(86.29)$ & NR & $342(99.4)$ \\
\hline \multirow{2}{*}{$\begin{array}{l}\text { Total withdra- } \\
\text { wal time (SD) } \\
\text { in min }\end{array}$} & AIAC & & $6.89(1.79)$ & $6.38(2.48)$ & $7.46(2.02)$ & $6.82(1.78)$ & NR & $6.95(1.68)$ \\
\hline & $\mathrm{CC}$ & & $6.39(1.21)$ & $4.76(2.54)$ & $6.99(1.57)$ & $6.74(1.62)$ & NR & $7.25(2.48)$ \\
\hline \multirow{2}{*}{$\begin{array}{l}\text { No polyp with- } \\
\text { drawal time } \\
\text { (SD) }\end{array}$} & AIAC & & $6.18(1.38)$ & NR & $6.48(1.32)$ & $6.37(0.98)$ & $\begin{array}{l}7.03 \\
(1.01)\end{array}$ & - \\
\hline & CC & & $6.07(1.11)$ & NR & $6.37(1.09)$ & $6.32(1.09)$ & $5.68(1.26)$ & - \\
\hline
\end{tabular}

AIAC, artificial intelligence-aided colonoscopy; CC, conventional colonoscopy; NR, not rated. 


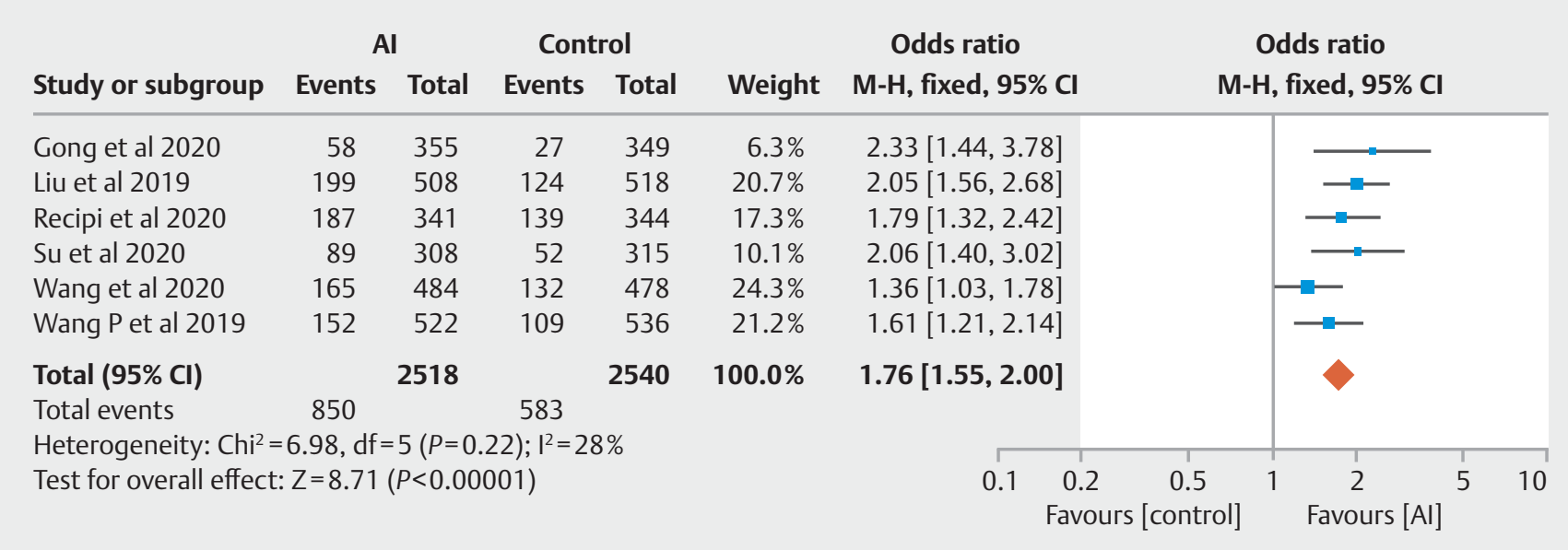

Fig. 2 Forest plot for studies assessing the effect on artificial intelligence-aided colonoscopy compared to control (conventional colonoscopy) on adenoma detection rate. $\mathrm{Cl}$, confidence interval.

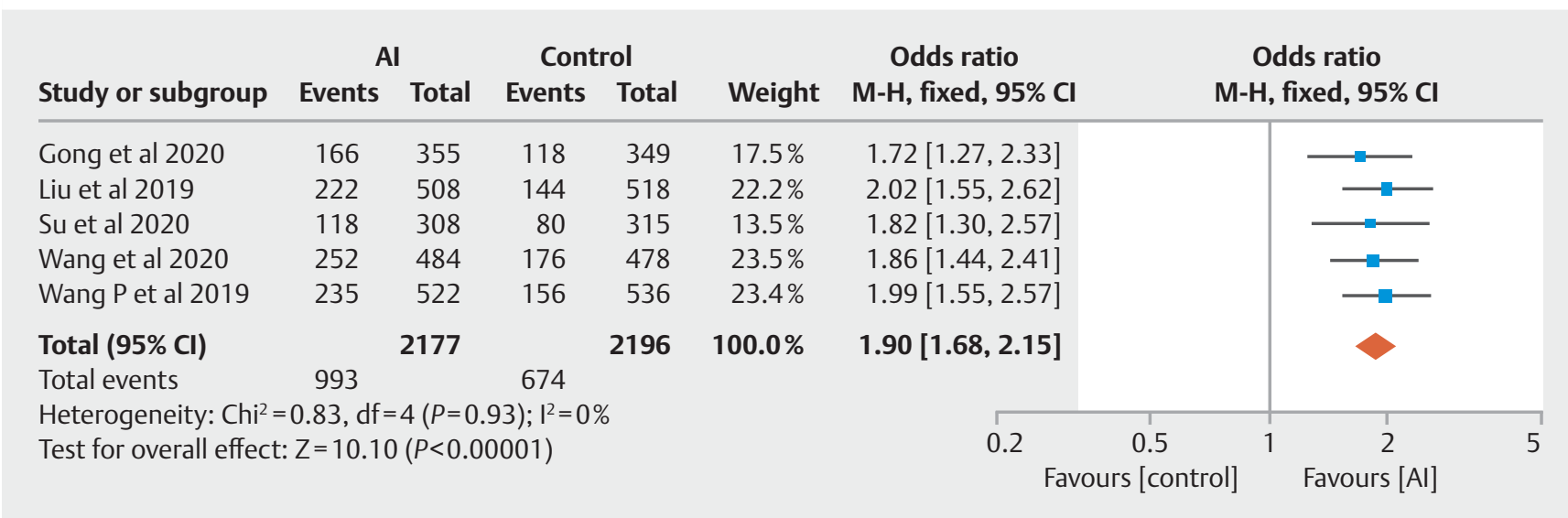

Fig. 3 Forest plot for studies assessing the effect on artificial intelligence-aided colonoscopy compared to control (conventional colonoscopy) on polyp detection rate. $\mathrm{Cl}$, confidence interval.

- Table 3 Outcomes of pooled analysis comparing AIAC vs CC.

\begin{tabular}{|l|l|l|l|}
\hline Outcome & No of studies & Odds ratio (AIAC vs CC) $\mathbf{( 9 5} \% \mathbf{C I})$ & Heterogeneity $\mathbf{I}^{\mathbf{2}}$ \\
\hline Adenoma detection rates & 6 & $1.76[1.55-2.00]$ & $28 \%$ \\
\hline Polyp detection rates & 5 & $1.90[1.68-2.15]$ & $0 \%$ \\
\hline Proximal colon ADR & 5 & $1.81[1.57-2.10]$ & $0 \%$ \\
\hline Distal colon ADR & 5 & $1.96[1.70-2.27]$ & $0 \%$ \\
\hline AIAC, artificial intelligence-aided colonoscopy; CC, conventional colonoscopy; ADR, adenoma detection rate; & \\
\hline
\end{tabular}

In the analyses based on adenoma size $(0-5 \mathrm{~mm}, 6-10$, and $\geq 10 \mathrm{~mm}$ ), AIAC improved ADR in all categories compared to CC. Advanced adenomas (defined as an adenoma that measures 10 $\mathrm{mm}$ or more in size, contains a substantial villous component, or exhibits high-grade dysplasia) are associated with an increased risk of CRC. [35]. As AIAC increased the detection of adenomas $\geq 10 \mathrm{~mm}$ compared to CC (OR 1.79; 1.27-2.53; $P<$ $\left.0.001, i^{2}=12 \%\right)$, it may further help in reducing interval CRC (Supplementary Table 1).

One of the biggest challenges besides cost and logistical consideration to use AIAC is the concern for increased WT. In the current meta-analysis, 1) the increase in total WT with AIAC was minimal, and 2) the no polyp WT was similar between AIAC and CC. WT may be used as a surrogate marker for adequate colon exam, and an increase in total WT with AIAC is 


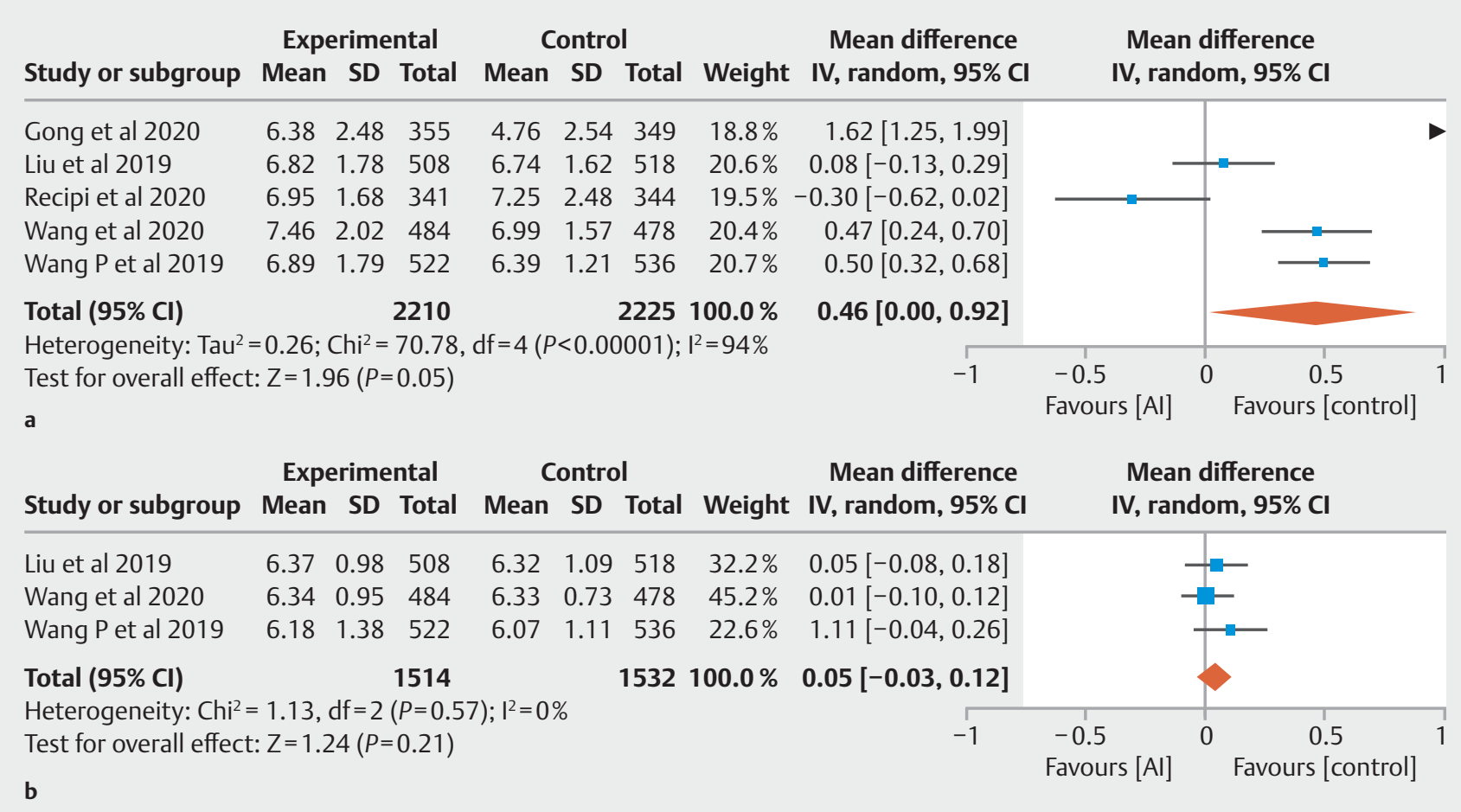

- Fig. 4 Forest plot for studies assessing the effect on artificial intelligence-aided colonoscopy compared to control (conventional colonoscopy) on a overall withdrawal time and $\mathbf{b}$ no polyp withdrawal time. $\mathrm{Cl}$, confidence interval.

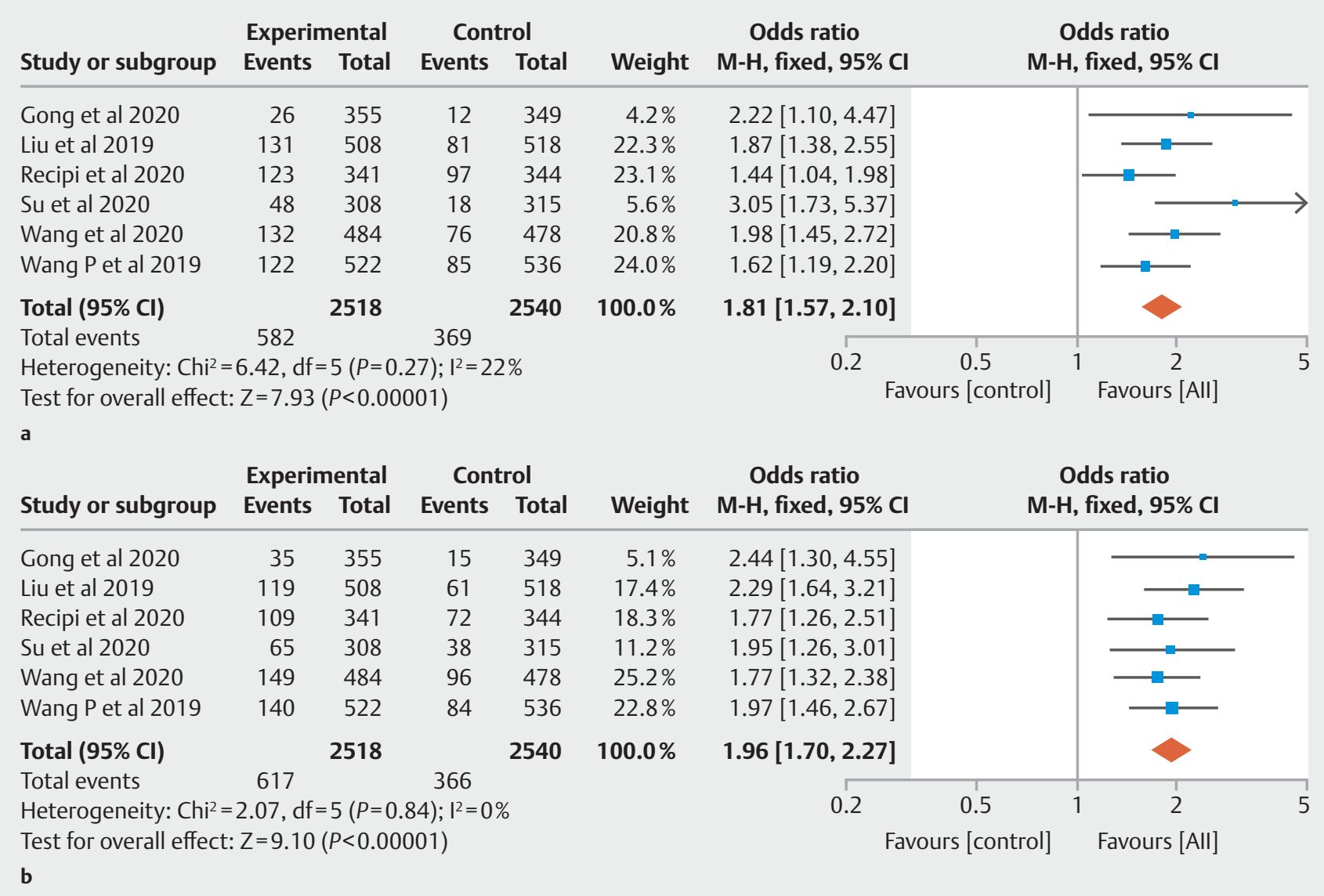

- Fig. 5 Forest plot for studies assessing the effect on artificial intelligence-aided colonoscopy compared to control (conventional colonoscopy) on a proximal colon adenoma detection rate and $\mathbf{b}$ distal colon adenoma detection rate. $\mathrm{Cl}$, confidence interval. 
probably related to increased polyp/adenoma detection and subsequent polypectomy compared to the CC group. The U.S. Multi-Society Taskforce (MSFT) on CRC recommends at least a 6-minute WT, but the compliance is not uniform. Although the use of AIAC increased the WT by 47 seconds, the overall WT with AIAC was $6.92 \pm 1.99$ minutes, which is well within the range of recommended by MSFT.

There are several limitations to the current meta-analysis. All but one study was from China and hence the generalizability of the meta-analysis results in the Western population is uncertain. There was moderate heterogeneity $\left(I^{2}=28 \%\right)$ in the pooled analysis of ADR. However, in the analyses of specific ADR based on location (proximal vs. distal colon) and size $(<5 \mathrm{~mm}, 5-10 \mathrm{~mm},>10 \mathrm{~mm})$ of polyps, the heterogenicity is low. Different DNN systems were used in the included studies, and it could contribute to heterogeneity. While there was substantial heterogeneity in the pooled analysis of WT $\left(I^{2}=94 \%\right)$, there was no heterogeneity $\left(I^{2}=0\right)$ in the pooled analysis of no polyp WT. We were unable to assess the impact of AIAC in improving ADR when the prep was inadequate, as individual studies did not report separate ADRs when the prep was inadequate (for both AIAC and CC groups). The included studies did not report data on costs associated with AIAC and cost-effectiveness, which are important considerations in screening programs.

The strengths of this review are as follows: systematic literature search with well-defined inclusion and exclusion criteria, rigorous evaluation of the risk of bias using the Cochrane tool, and assessment of the quality of evidence using the GRADE approach. Only RCTs were included in the meta-analyses to improve the reliability of our pooled estimates for real-time use of Al. In addition to estimating the impact of AIAC on overall ADR, we also performed separate analyses to estimate specific ADRs based on location and size of polyps. There was low heterogeneity noted in analyses of most outcomes.

\section{Conclusion}

In conclusion, the use of AIAC significantly improves ADR and PDR compared to CC with minimal increase in WT. AIAC also improves the detection of polyps in the proximal colon and large polyps (>10 mm). Hence, the use of AIAC could potentially decrease the incidence of interval cancers. Future studies are needed in the Western population to confirm the generalizability of the current meta-analysis results. Further studies are also needed on the cost-effectiveness of AIAC.

\section{Competing interests}

The authors declare that they have no conflict of interest.

\section{References}

[1] Siegel RL, Miller KD, Goding Sauer A et al. Colorectal cancer statistics. CA: A Can J Clin 2020: doi:10.3322/caac.21601
[2] Bibbins-Domingo K, Grossman DC, Curry S] et al. Screening for Colorectal Cancer: US Preventive Services Task Force Recommendation Statement. JAMA 2016; 315: 2564-2575

[3] Rex DK, Boland CR, Dominitz JA et al. Colorectal Cancer Screening: Recommendations for Physicians and Patients from the U.S. MultiSociety Task Force on Colorectal Cancer. Am J Gastroenterol 2017; 112: 1016-1030

[4] Doubeni CA, Corley DA, Quinn VP et al. Effectiveness of screening colonoscopy in reducing the risk of death from right and left colon cancer: a large community-based study. Gut 2018; 67: 291-298

[5] Barret M, Chaussade S, Coriat R. Adenoma detection rate and risk of colorectal cancer and death. N Engl J Med 2014; 370: 2540-2541

[6] Rex DK, Schoenfeld PS, Cohen J et al. Quality indicators for colonoscopy. Gastrointest Endosc 2015; 81: 31-53

[7] Ahn SB, Han DS, Bae JH et al. The miss rate for colorectal adenoma determined by quality-adjusted, back-to-back colonoscopies. Gut Liver 2012; 6: 64-70

[8] Aslanian HR, Shieh FK, Chan FW et al. Nurse observation during colonoscopy increases polyp detection: a randomized prospective study. Am J Gastroenterol 2013; 108: 166-172

[9] Gong D, Wu L, Zhang J et al. Detection of colorectal adenomas with a real-time computer-aided system (ENDOANGEL): a randomised controlled study. Lancet Gastroenterol Hepatol 2020; 5: 352-361

[10] Liu WN, Zhang YY, Bian XQ et al. Study on detection rate of polyps and adenomas in artificial-intelligence-aided colonoscopy. Saudi J Gastroenterol 2020; 26: 13-19

[11] Su JR, Li Z, Shao XJ et al. Impact of a real-time automatic quality control system on colorectal polyp and adenoma detection: a prospective randomized controlled study (with videos). Gastrointest Endosc 2020; 91: 415-424.e414

[12] Wang P, Berzin TM, Glissen Brown JR et al. Real-time automatic detection system increases colonoscopic polyp and adenoma detection rates: a prospective randomised controlled study. Gut 2019; 68: 1813-1819

[13] Wang P, Liu X, Berzin TM et al. Effect of a deep-learning computer-aided detection system on adenoma detection during colonoscopy (CADe-DB trial): a double-blind randomised study. Lancet Gastroenterol Hepatol 2020; 5: 343-351

[14] Kriegeskorte N, Golan T. Neural network models and deep learning. Curr Biology 2019; 29: R231-R236

[15] Mori Y, Kudo SE, Chiu PW et al. Impact of an automated system for endocytoscopic diagnosis of small colorectal lesions: an international web-based study. Endoscopy 2016; 48: 1110-1118

[16] Urban G, Tripathi P, Alkayali T et al. Deep learning localizes and identifies polyps in real time with $96 \%$ accuracy in screening colonoscopy. Gastroenterology 2018; 155: 1069-1078.e1068

[17] Mori Y, Kudo SE, Wakamura K et al. Novel computer-aided diagnostic system for colorectal lesions by using endocytoscopy (with videos). Gastrointest Endosc 2015; 81: 621-629

[18] Byrne MF, Chapados N, Soudan F et al. Real-time differentiation of adenomatous and hyperplastic diminutive colorectal polyps during analysis of unaltered videos of standard colonoscopy using a deep learning model. Gut 2019; 68: 94-100

[19] Schünemann H, Brozek J, Guyatt G, Oxman A. Handbook for grading the quality of evidence and the strength of recommendations using the GRADE approach. Available at: https://gdt.gradepro.org/app/ handbook/handbook.html

[20] Higgins JPT, Altman DG, Gøtzsche PC et al. The Cochrane Collaboration's tool for assessing risk of bias in randomised trials. BMJ 2011; 343: d5928

[21] Stang A. Critical evaluation of the Newcastle-Ottawa scale for the assessment of the quality of nonrandomized studies in meta-analyses. Eur J Epidemiol 2010; 25: 603-605 
[22] Easterbrook P], Berlin JA, Gopalan R et al. Publication bias in clinical research. Lancet (London, England) 1991; 337: 867-872

[23] Klare P, Sander C, Prinzen M et al. Automated polyp detection in the colorectum: a prospective study (with videos). Gastrointest Endosc 2019; 89: 576-582.e571

[24] Repici A, Badalamenti M, Maselli R et al. Efficacy of real-time computer-aided detection of colorectal neoplasia in a randomized trial. Gastroenterology 2020: doi:10.1053/j.gastro.2020.04.062

[25] Zauber AG, Winawer SJ, O'Brien MJ et al. Colonoscopic polypectomy and long-term prevention of colorectal-cancer deaths. N Engl J Med 2012; 366: 687-696

[26] Pohl H, Robertson DJ. Colorectal cancers detected after colonoscopy frequently result from missed lesions. Clin Gastroenterol Hepatol 2010; 8: 858-864

[27] Lanspa SJ, Lynch HT. Quality indicators for colonoscopy and the risk of interval cancer. N Engl J Med 2010; 363: 1371, author reply 1373

[28] Corley DA, Jensen CD, Marks AR et al. Adenoma detection rate and risk of colorectal cancer and death. N Engl J Med 2014; 370: 12981306

[29] Aziz M, Sharma S, Fatima R et al. How to increase proximal adenoma detection rate: a meta-analysis comparing water exchange, water immersion and air/CO2 insufflation methods for colonoscopy. Ann Gastroenterol 2020; 33: 178-186
[30] Lawrence Z, Gross SA. The use of attachment devices to aid in adenoma detection. Curr Treatment Options Gastroenterol 2020: doi:10.1007/s11938-020-00280-4

[31] Atkinson NSS, Ket S, Bassett $P$ et al. Narrow-band imaging for detection of neoplasia at colonoscopy: a meta-analysis of data from individual patients in randomized controlled trials. Gastroenterol 2019; 157: 462-471

[32] Aziz M, Desai M, Hassan S et al. Improving serrated adenoma detection rate in the colon by electronic chromoendoscopy and distal attachment: systematic review and meta-analysis. Gastrointest Endosc 2019; 90: 721-731.e721

[33] Brenner $\mathrm{H}$, Hoffmeister $\mathrm{M}$, Arndt $\mathrm{V}$ et al. Protection from right- and left-sided colorectal neoplasms after colonoscopy: population-based study. J Natl Cancer Inst 2010; 102: 89-95

[34] Nakagawa-Senda H, Hori M, Matsuda T et al. Prognostic impact of tumor location in colon cancer: the Monitoring of Cancer Incidence in Japan (MCIJ) project. BMC Cancer 2019; 19: 431

[35] Brenner $\mathrm{H}$, Hoffmeister M, Stegmaier $\mathrm{C}$ et al. Risk of progression of advanced adenomas to colorectal cancer by age and sex: estimates based on 840,149 screening colonoscopies. Gut 2007; 56: 15851589 